\title{
Chlorophyll $d$ production in crushed algae in aqueous acetone
}

\author{
Shinya Akutsua, Hirohisa Komatsua, Daiki Fujinumaa, \\ Hideaki Miyashita $^{\mathrm{b}}$, Koji Iwamoto ${ }^{\mathrm{c}}$, Yoshihiro Shiraiwa ${ }^{\mathrm{c}}$, and Masami Kobayashi ${ }^{\mathrm{a}}$ *
}
"Division of Materials Science. Faculty of Pure and Applied Science, University of Tsukuba. Japan: ${ }^{h}$ Graduate School of Human and Environmental Studies, Kvoto University, Japan. "Faculty of Life and Environmental Sciences, University of Tsukuba. Japan;

(*Corresponding author. Tel: +81-298-53-6940; FAX: +81-298-53-4490; E-mail: masami@ims.tsukuba.ac.jp)

\begin{abstract}
We for the first time report on the $\mathrm{Chl}$ a to $\mathrm{Chl} d$ conversion in crushed algae. Synechoctstis sp. PCC6803, Emiliania huxlevi. Gephrocapsa oceanica, Isochrisis galhana. Helladosphaera comifera. Pleurochrisis carterae. Chlorella vulgaris and Chlamidomonas acidophila, incubated in aqueous acetone at $303 \mathrm{~K}$ for 2 days, where no $\mathrm{Chl}$ a was added externally to the system. The highest conversion of $\mathrm{Chl}$ a into $\mathrm{Chl} d$ was observed in $\left(j\right.$. oceanica $\left(c a .1 .1^{\prime \prime}\right)$. The conversion yield was lower, when other algae were used: S. sp. PCC6803 (ca. 0.4\%). E. huxleri (ca. 0.3\%), C. vulgaris (ca. 0.2\%), I. galbana (ca. $0.1 \%)$, H. cornifera (ca. 0.1\%). P. curterce (ca. $0.06 \%)$ and $C$. acidophila $(c a .0 .04 \%)$. The well-known degradation reactions of Chl $a$. namely. pheophytinization ( $\mathrm{Chl} a \rightarrow$ Phe $a$ ) and epimerization $\left(\mathrm{Chl} a \rightarrow\left(\mathrm{hl} a^{\prime}\right)\right.$. were also observed. We should pay enough attention to the fact that (hl $d$ was not detected at all in the initial algate examined here. It is interesting to note that $\mathrm{Chl} d . \mathrm{Chl} d^{\prime}, \mathrm{Chl} a^{\prime}$ and Phe a were also detected in processed algae food. Chlorclla powder and dried laver. It is noteworthy that these artifacts function as kev components in natural photosynthesis.
\end{abstract}

\section{Introduction}

In 1943, Chl d (Fig. 1) was first discovered in some species of red algae (Manning and Strain, 1943). The molecule structure was then identified to be 3-desvinyl-3-formyl-Chl $a$ (Holt and Morley, 1959; Holt 1961). Since $\mathrm{Chl} d$ was not found in all red algae, Chl $d$ had been hence thought to be an oxidative artifact of Chl a (Fig. 1).

A Chl $d$-dominated cyanobacterium. Acarochloris marina. was accidentally discovered in 1993 (Miyashita et al., 1996: Ohashi er al., 2008). Chl $d$ is expected to be oxidatively biosynthesized from $\mathrm{Chl} a$, where oxidative cleavage of the $\mathrm{C}=\mathrm{C}$ double bond of a vinyl group of $\mathrm{Chl} a$ at ring $\mathrm{I}$ $\left(-\mathrm{CH}=\mathrm{CH}_{2} \rightarrow-\mathrm{CHO}\right)$ is required, while the biosynthetic pathway of $\mathrm{Chl} d$ in $A$. marina has not yet been clarified. Chl $a$ has many $\mathrm{C}=\mathrm{C}$ bonds in the macrocycle (Fig. 1), and hence it is too difficult to oxidize only the $\mathrm{C}=\mathrm{C}$ bond in the $-\mathrm{CH}=\mathrm{CH}_{2}$ moiety at ring I. Usually, both a special metal complex $\left(\mathrm{OsO}_{4}\right)$ and an oxidant $\left(\mathrm{H}_{5} \mathrm{IO}_{6}\right)$ are needed for the selective oxidation (Mironov et al., 2004).

Recently, we came across the formation of Chl $d$ from Chl $a$ with papain (EC 3.4.22.2) in several aqueous organic solvents (Kobayashi et al., 2005; Koizumi et al., 2005; Okada et al., 2009; Ohashi et

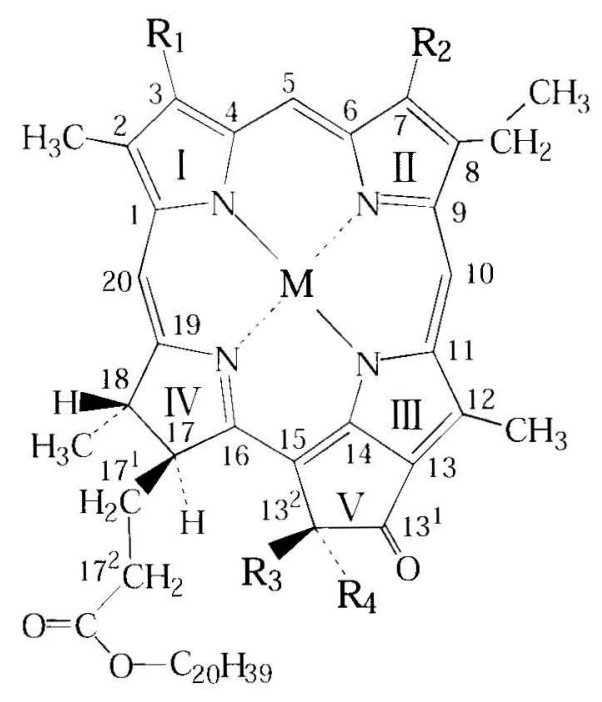

\begin{tabular}{|c|c|c|c|c|c|}
\hline & $\mathbf{M}$ & $\mathbf{R}_{1}$ & $\mathbf{R}_{2}$ & $\mathbf{R}_{3}$ & $\mathbf{R}_{\downarrow}$ \\
\hline Chl $a$ & $\mathbf{M g}$ & $\mathrm{CH}=\mathrm{CH}_{2}$ & $\mathrm{CH}_{3}$ & $\mathbf{H}$ & $\mathrm{COOCH}_{3}$ \\
\hline Chl $a^{\prime}$ & $\mathbf{M g}$ & $\mathrm{CH}=\mathrm{CH}_{2}$ & $\mathrm{CH}_{3}$ & $\mathrm{COOCH}_{3}$ & H \\
\hline Phe $a$ & $2 \mathrm{H}$ & $\mathrm{CH}=\mathrm{CH}_{2}$ & $\mathrm{CH}_{3}$ & H & $\mathrm{COOCH}_{3}$ \\
\hline Chl $b$ & $\mathbf{M g}$ & $\mathrm{CH}=\mathrm{CH}_{2}$ & СHO & H & $\mathrm{COOCH}_{3}$ \\
\hline Chl $d$ & $\mathbf{M g}$ & $\mathrm{CHO}$ & $\mathrm{CH}_{3}$ & H & $\mathrm{COOCH}_{3}$ \\
\hline Chl $d^{\prime}$ & Mg & $\mathrm{CHO}$ & $\mathrm{CH}_{3}$ & $\mathrm{COOCH}_{3}$ & $\mathbf{H}$ \\
\hline
\end{tabular}

Fig. 1 Molecular structures of chlorophylls, according to the IUPAC numbering system.

al., 2010). The Chl $a$ to Chl $d$ conversion was not observed when $\mathrm{Chl} a$ was incubated with esterases 
(esterase EC 3.1.1.1, cholesterol esterase EC 3.1.1.13, phosphatase EC 3.1.3.2) and other proteases ( $\alpha$-chymotrypsin EC 3.4.21.1, subtilisin carlsberg EC 3.4.21.14, ficin EC 3.4.22.3, bromelain EC 3.4.22.4) (Koizumi et al., 2005: Okada et al.. 2009).

Quite recently, the same conversion was observed when $\mathrm{Chl} a$ was incubated with horseradish peroxidase (Fujita et al., 2012). Further, we found that $\mathrm{Chl} a$ was nonenzymatically converted into $\mathrm{Chl} d$ in acetone $/ 0.3 \% \mathrm{H}_{2} \mathrm{O}_{2}(10 / 1 . v / v)$ (Fujita et al. . 2012).

The Chl $a$ into $\mathrm{Chl} d$ conversion was also observed when $\mathrm{Chl}$ a was incubated with several grated vegetables (Itoh et al., 2011). In particular, Japanese radish (root) showed higher conversion than papain.

In order to clarify the conversion mechanisms in vitro and the birth of $\mathrm{Chl} d$ in nature. we incubated several crushed microalgae in acetone $\mathrm{H}_{2} \mathrm{O}(5 / 1$. 1/1) at $303 \mathrm{~K}$ for $48 \mathrm{~h}$ in the dark, and the $\mathrm{Chl} a$ into $\mathrm{Chl} d$ conversion was seen in all crushed algae examined. even no additional $\mathrm{Chl} a$ was added to the system.

\section{Materials and Methods}

Incubation of crushed algae in aqueous acetone

Eight species of microalgae. Sinechocistis sp.

PCC6803. Emiliania huxlevi. Gephrorapsa oceanica, Isochrysis galhana, Helladosphaera connifera. Pleurochrnsis carterae, Chlorella vulgaris and Chlamydomonas acidophila were sonicated in acetone/water $\left(5 / 1, \mathrm{~V} / \mathrm{L}^{\circ}\right)$ for $30 \mathrm{~s}$ at $277 \mathrm{~K}$, and then shaken gently at $303 \mathrm{~K}$ in the dark.

\section{Pigment analysis}

Samples were taken periodically and filtered by poly(tetrafluoroethylene) membrane tilters. The filtrate was injected into a reversed-phase Senshupak PEGASIL-ODS HPLC column $(4.6 \mathrm{~mm}$ ID x 250 $\mathrm{mm}$ ) cooled to $277 \mathrm{~K}$ in an ice-water bath. The pigments were eluted isocratically with degassed ethanol/methanol/2-propanol/water( $86 / 13 / 1 / 3,1 / 1 / 1 / 1)$ at a flow rate of $0.3 \mathrm{~mL} / \mathrm{min}$, and were monitored with a JASCO Multiwavelength MD-2015 detector $(\lambda$ $=300-800 \mathrm{~nm}$ ).

In the case of commercially available processed algae, Chlorella powder and dried laver. they were ground in a glass mortar for $1 \mathrm{~min}$ at $277 \mathrm{~K}$. Pigments were extracted from the ground materials by sonication in an acetone/methanol $(7 / 3, v / v)$ mixture for $2 \mathrm{~min}$ in the dark at room temperature. The extract was filtered and dried in vacuo. The thus-obtained solid material was immediately dissolved in $10 \mu \mathrm{L}$ of chloroform, and injected into a silica HPLC column (YMC-pack SIL. $250 \times 4.6$ $\mathrm{mm}$ ID) cooled to $277 \mathrm{~K}$ in an ice-water bath. The pigments were eluted isocratically with degassed hexane/2-propanol/methanol $(100 / 0.7 / 0.25,1 / 1 / 1)$ at a flow rate of $0.9 \mathrm{~mL} / \mathrm{min}$. and were monitored with a JASCO UV-970 detector $(\lambda=700 \mathrm{~nm})$ and a JASCO Multiwavelength MD-915 detector $(\lambda=300-800$ $\mathrm{nm}$ ) in series.

\section{Results and Discussion}

\section{Chl d produced from chl a in crushed algae}

Typical HPLC traces for crushed algae incubated in aqueous acetone at $303 \mathrm{~K}$ for 2 days are shown in Fig. 2. The conversion of $\mathrm{Chl} a$ into $\mathrm{Chl} d$ was observed in all algae examined here (Figs. $\left.2 \mathrm{~A}^{\prime}-\mathrm{H}^{\prime}\right)$. even though no additional $(\mathrm{hl} a$ was added to the system. The results indicate that $\mathrm{Chl} a$ present originally in these algae was directly converted to $\mathrm{Chl} d$ by the reaction with something present in the algae. We should note that $\mathrm{Chl}$ ct was not detected at all in the initial algae cxamined here (Figs. 2A-H).

The highest conversion of $\mathrm{Chl} a$ into Chl $d$ was observed in G. oceunica (ca. 1.1\%, Fig. 2N'). G. oceanica almost equals papain (ca. 2\%. Kobayashi et al. 2005: Koizumi ot al. 2005: Okada et al., 2009; Ohashi et al. 2010) in efficiency.

The conversion yields were lower in other crushed algae: S. sp. PCC6803 (ca. 0.4\%. Fig. 2F'). E. huxlevi (ca. 0.3\%. Fig. 2B'). C. rulgaris (ca. 0.2\%, Fig. 2G). I. galthana (ca. ().1\%. Fig. 2('). H. cornifera (ca. 0.1\%. Fig. 2D'). P. carterae (ca. 0.06\%. Fig. 2E') and $C$. acidophila (ca. (0.04\%. Fig. $2 \mathrm{H}^{\prime}$ ), respectively.

Phe a and Chl a' produced as artifacts of Chl a in roushed algae

In our present study, familiar degradation reactions of $\mathrm{Chl} a$. namely, pheophytinization $(\mathrm{Chl} a$

- Phe (a) and epimerization $\left(\mathrm{Chl} a \rightarrow\left(\mathrm{Chl} a^{\prime}\right)\right.$, were also observed (Figs. 2A'- $\mathrm{H}^{\prime}$ ). In the case of $C$. vulgaris and $C$. acidophila, degradation products of $C h l b$. Phe $h$ and $C h l b$, were also produced, although the corresponding peaks are not seen in Figs. $2 \mathrm{G}^{\prime}$ and $\mathrm{H}^{\prime}$, because the amount was very small and the detection wavelength was $700 \mathrm{~nm}$.

\section{Chl d detected in processed algae}

In our present studies, an organic solvent, acetone, was used, but the natural world is not abundant in acetone. So we next examined the presence of $\mathrm{Chl} d$ in Chlorella powder and dried laver. because organic solvents including acetone are not 

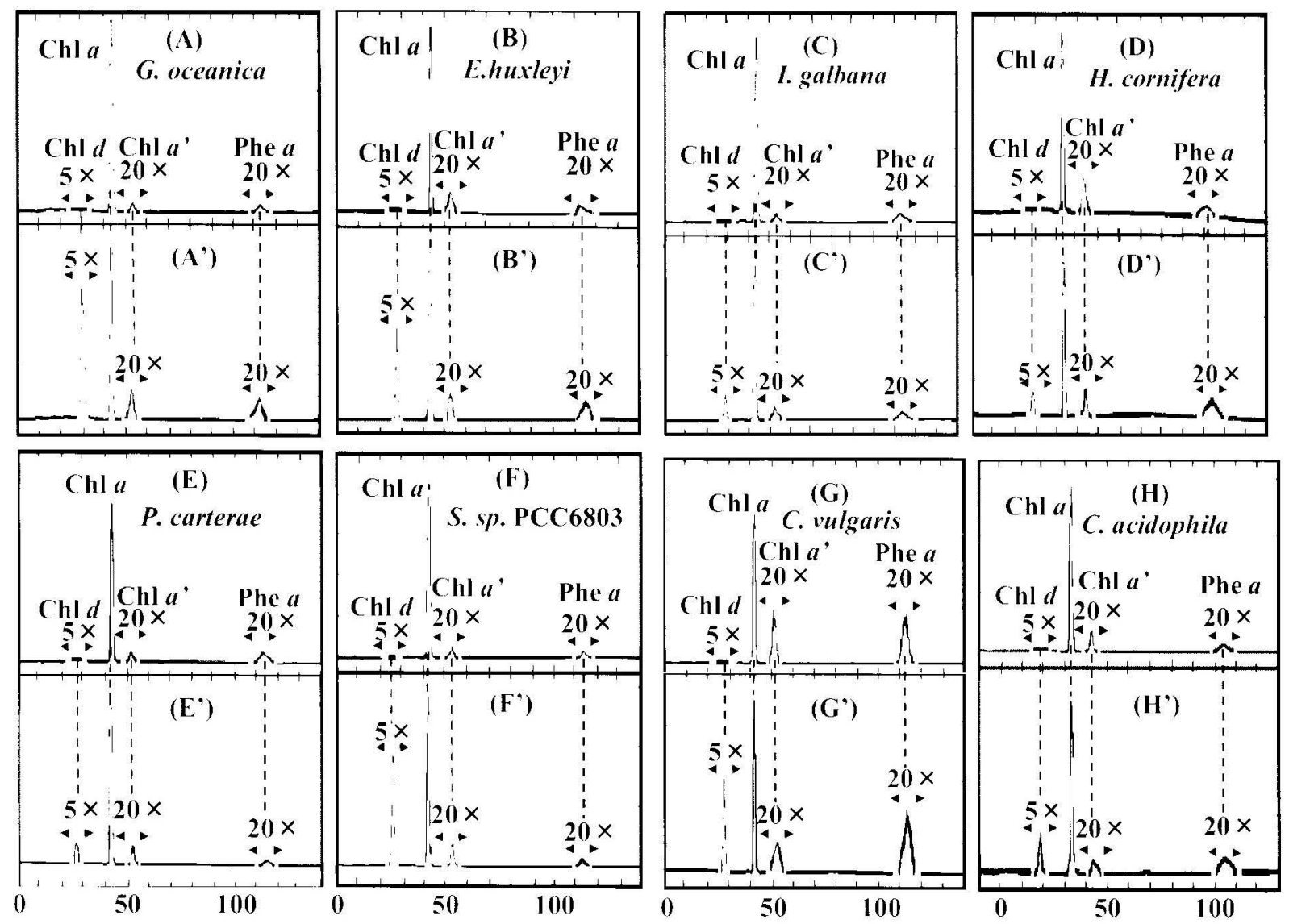

Retention time / min

Fig. 2 Rerersed-phase HPIC elution profiles for crushed algat incubated for 2 day in acetone waterflo I. .r. in the dark at $303 \mathrm{~K}$. Incubation times are () $\mathrm{h}(\mathrm{A}-1 \mathrm{H})$ and $48 \mathrm{~h}\left(\mathrm{~A}^{\circ}-\mathrm{H}^{\circ}\right)$. respectiscls. Detection wavelength is $70 \mathrm{n} \mathrm{nm}$

used to make such commercially available processed alga food.

Typical HPLC traces for Chlorella pouder and dried laver are shown in Fig. 3. In Chlorella powder. a small amount of Chl $d$ and Phe $d$ was observed (Fig. $3 \mathrm{~A})$. By contrast, in dried laver a considerable amount of $\mathrm{Chl} d$ and $\mathrm{Chl} d^{\prime}$ were clearly detected (Fig. 3B). Pheophytinization of $\mathrm{Chl}$ a seems to have proceeded in Chlorella powder processing (Fig. 3A). Chlorophyll $d$, Chl $d^{\prime}$. Phe $a^{\prime}$ and Phe $d$ seen in Fig. 3 are the artifacts of $\mathrm{Chl} a$ produced through processing. It is not clear whether Phe $d$ seen in Chlorella powder had been produced from Chl a followed by pheophytinization or directly from Phe a produced by pheophytinization of $\mathrm{Chl}$ a. Anyway. it is well worth noting that Chl $d$. Chl $d^{\prime}$ and Phe $d$ were produced from $\mathrm{Chl} a$ in the absence of acetone. meaning that organic solvents are not needed to convert Chl $a$ into Chl $d$-type pigments.

The present findings exhibit that the Chl a to Chl $d$ conversion is not a rare event in nature, and will provide new insight into the unsolved question as

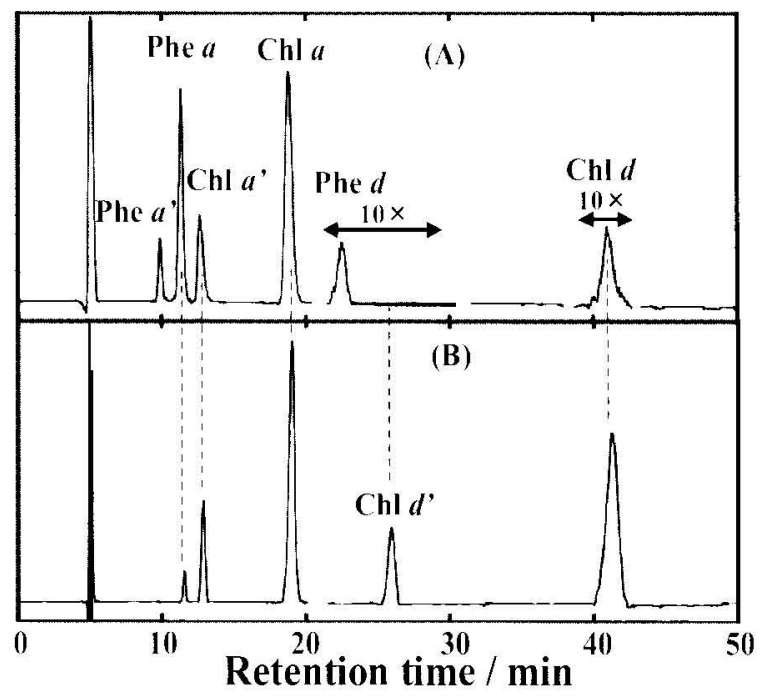

Fig. 3 Normat-phase HPI.C elution profiles for (A) Chlorella powder and $(B)$ dried laver: $\quad \lambda=700 \mathrm{~nm}$.

to the birth of $\mathrm{Chl} d$ in photosynthesis. We want to emphasize that $\mathrm{Chl} a$ artifacts, Phe $a$, Chl $a^{\prime}, \mathrm{Chl} d$ and $\mathrm{Chl} d^{\prime}$, function as key components in natural photosynthesis (Fig. 4). (Akiyama et al., 2001; Kobayashi et al., 2005; Ohashi et al., 2008, 2010). 


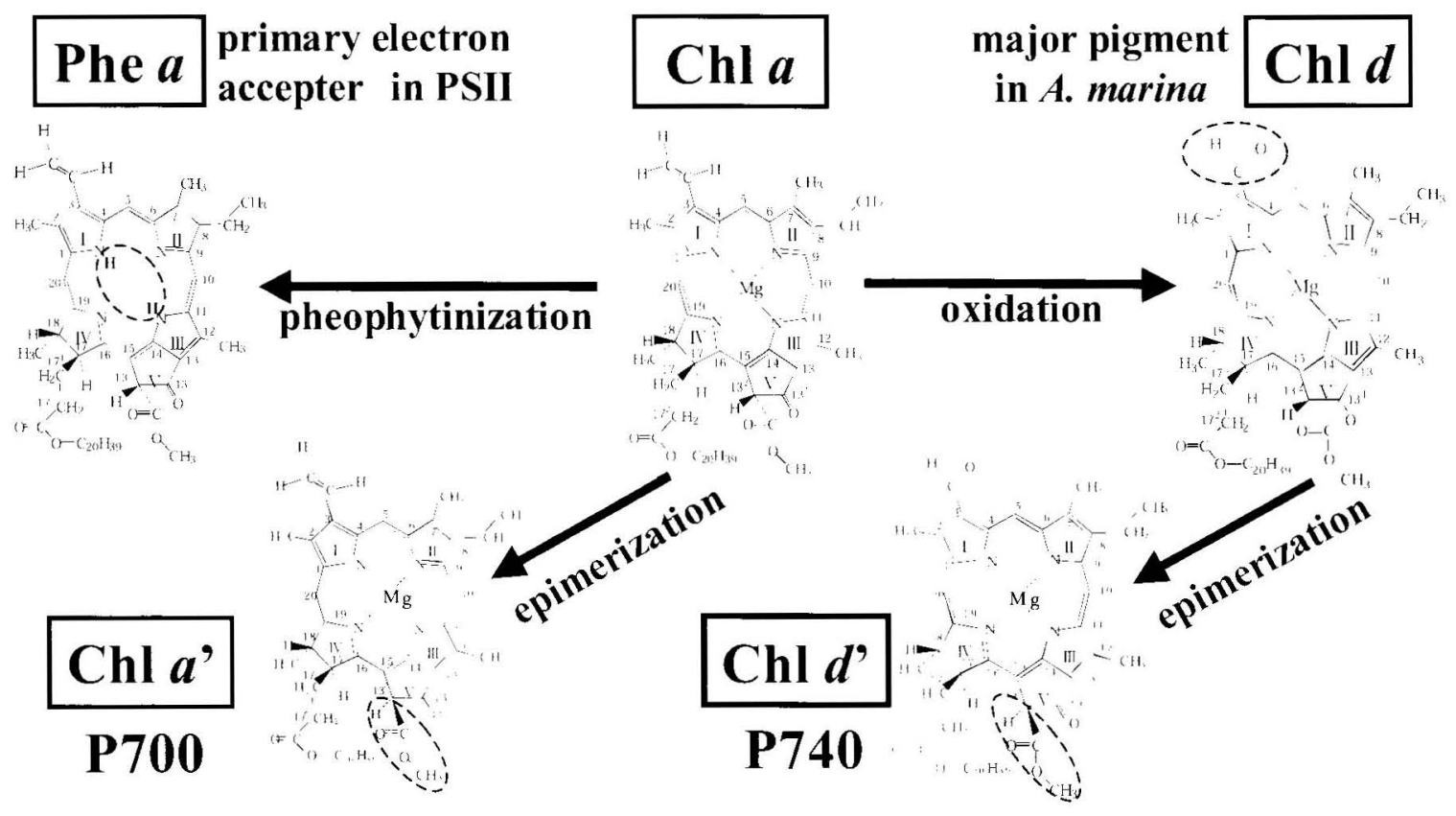

Fig. 4 Artifacts produced from $\mathrm{Chl}$ a and their function in natural photosynthesis.

\section{Acknowledgements}

We are grateful to Mr. Daisuke Fukayama for their help with the preparation of the manuscript. This work was supported in part by Special Project of Organization for the Support and Development of Strategic Initiatives (Green Innovation) (Univ. Tsukuba) to M.K.

\section{References}

Akiyama M, Miyashita H. Watanabe T, Kise H, Miyachi S and Kobayashi M (200l) Detection of chlorophyll $d^{\prime}$ and pheophytin $a$ in a chlorophyll $d$-dominating oxygenic photosynthetic prokaryote Acaryochloris marina. Anal Sci, 17; 205-208

Fujita K, Aoki K, Itoh S, Hotota Y, Nakazato M, Iwamoto K, Shiraiwa $Y$, Miyashita $H$, Kobayashi M(2012) Nonenzymatic and enzymatic formation of $\mathrm{Chl} d$ from $\mathrm{Chl}$ a in vitro. Photomed Photobiol, 34; 31-35

Holt AS(1961) Further evidence of the relation between 2-desvinyl-2-formyl-chlorophyll $a$ and chlorophyll d. Can J Botany, 39; 327-331

Holt AS and Morley HV (1959) A proposed structure for Chlorophyll d. Can J Chem, 37: 507-514

Itoh S, Aoki K, Fujita K, Miyashita $\mathrm{H}$ and Kobayashi M (2011) Conversion of Chl $a$ into Chl $d$ catalyzed by extract of vegetables. Jpn SoC Photosynth Res, 21(2); 65-69 (in Japanese)

Kobayashi M, Watanabe S, Gotoh T, Koizumi H, Itoh Y, Akiyama M, Shiraiwa Y, Tsuchiya T, Miyashita H, Mimuro M, Yamashita $T$ and Watanabe T (2005) Minor but key chlorophylls in
Photosystem II. Photosinth Res, 84: 201-207

Koizumi H, Itoh Y. Hosoda S, Akiyama M. Hoshino

T, Shiraiwa Y, Kobayashi M (2005) Serendipitous discovery of $\mathrm{Chl} d$ formation from Chl a with papain. Sci Tech Adv Material. 6; $551-557$

Manning WM and Strain HH (1943) Chlorophyll $d$, a green pigment of the red algae. $J$ Biol Chem, 151; $1-19$

Mironov AF. Ruziev RD and Lebedeva VS (2004) Synthesis and chemical transformations of N-Hydroxy- and N-Hydroxyalkylcycloimides of chlorin p6. Russian J Bioorganic Chemistry, 30; 466-476

Miyashita H, Ikemoto H. Kurano N. Adachi K, Chihara M and Miyachi S (1996) Chlorophyll $d$ as a major pigment. Nature, $383 ; 402$

Ohashi S, Miyashita H, Okada N, T. Iemura, Watanabe T, Kobayashi M(2008) Unique photosystems in Acarvochloris marina. Photosynth Res. 98; 141-149

Ohashi S, lemura T. Okada N, Itoh S, Furukawa H, Okuda M, Ohnishi-Kameyama M, Ogawa T, Miyashita $H$. Watanabe T, Itoh S, Oh-oka H, Inoue K, Kobayashi M (2010) An overview on chlorophylls and quinones in the photosystem l-type reaction centers. Photosynth Res, 104; 305-319

Okada N, Itoh S, Nakazato M, Miyashita H, Ohashi S, Kobayashi M (2009) Effective hydrolysis of chlorophyll a to yield chlorophyllide $a$ by papain in aqueous acetone. Current Topics in Plant Biologv, 10; 47-52 